substantial, extending to archaeological comparisons. The ethno-archaeological chapters are among the most readable, dealing with the well-known hunters of Africa and their present problems as well as their technology. Hunting practices of Venezuela and the Philippines also feature. World coverage cannot be comprehensive, but fortunately some authors give broad surveys. Pierre Cattelain, for example, discusses Australian technologies in his study of the Upper Palaeolithic, and provides numerous references.

Both editor and contributors have done well, despite a slightly wooden format, now too common, and probably imposed by publishers or a growing convention. Editors should have their say - but just once. When they write introductions to each and every section, and even to the concluding retrospective chapter, it implies that formula is more important than effective use of space. A concluding chapter is useful, however, and Margaret Nelson makes many pertinent comments, dealing en passant with sexism: if studies of projectiles and hunting tended to be by men about men, excellent studies here and elsewhere show that there is no good reason for that.

One has to be enthusiastic about the scholarly value of a book so packed with information and case studies. Spears and arrowheads, exotic and mundane, are all here, together with many analyses of hunting trips and decision paths, which are invaluable in showing how hunter-gatherers spend their time, and how they get their returns.

John A. J. Gowlett is in the Department of

Archaeology, University of Liverpool,

Liverpool L69 3BX, UK.

\section{Technological heaven}

\section{The Religion of Technology: The Divinity of Man and the Spirit of Invention}

by David F. Noble

Knopf: 1997. Pp. 273. \$26

\section{How ard P.Segal}

The centuries-old belief in unceasing technological progress leading to Utopia has often been equated with the religious belief in salvation or perfection through divine intervention. Similarly, engineers and inventors have repeatedly been characterized as secular deities in their reputed ability to transform the world.

Had David F. Noble contented himself with merely updating this ideology as it applies to endeavours since the Second World War in nuclear weapons, space flight, artificial intelligence and genetic engineering, he would have had an interesting but hardly original book. Instead, he has also provided a ground- breaking account of the religious, especially Christian, roots of Western technology from medieval times to the present day.

Rejecting the still common assumption that religion and technology, like religion and science, have always been antagonistic, Noble shows how major Western technological advances, like major Western scientific discoveries, have routinely been invested with religious significance. Many Western technological pioneers have linked their achievements with the recovery of human divinity, lost after Adam's fall.

For Noble, the 'religion of technology' is not a mere metaphor but a fact of life. What, for obscure reasons, began in the early Middle Ages as the linkage by Benedictine monks of redemption with the 'useful arts' - windmills, watermills, clocks, metal forges and ploughs, for example — steadily extended to most successive Western technologies. Given this revisionist ideological framework, it is hardly surprising to see twentieth-century technological élites increasingly eager to transcend earthly boundaries through space flight and to exercise God-like powers of genetic engineering and artificial intelligence.

These technological élites have been and remain overwhelmingly male, aggressively masculine in their culture and values. As important to Noble's revisionist argument as the bonding of Christian theology with technological advance is the exclusion of women from these technological crusades. Indeed, the ultimate dream of many of the visionaries he discusses is the creation through genetic engineering of a womanless world, an "Eden before Eve", as Noble put it in his 1992 book $A$ World Without Women: The Christian Clerical Culture of Western Science.

The Religion of Technology is a sequel to $A$ World Without Women, which traced the continuing inferior status of women in most scientific and technical fields back to the medieval Latin Church. After centuries of considerable gender equality, the Church began excluding women from the monasteries, scientific societies and early universities from which modern Western science sprang. Noble places excessive blame on Christianity, which was hardly unique among world religions and cultures in relegating women to second-class status, at best the curious objects of male 'scientific' attention.

But Noble's illumination of relative gender equality within pre-medieval Christianity reinforces the fundamental theme of all his writings: science and technology are always the products of human endeavours and decisions, not omnipotent forces. As Noble has repeatedly reminded us, those who invoke the omnipotence of science and technology invariably have vested interests in actually controlling scientific and technological applications. Consequently, notwithstanding the theological underpinnings detailed in both of Noble's works, nothing was inevitable - or 'natural' — about either the separate spheres created for men and women or the millenarian thrust of Western science and technology.

Like A World Without Women, The Religion of Technology relies heavily on secondary works, as Noble, a distinguished scholar of American technology, readily admits in the former volume but not in the latter. Perhaps to reassure readers that his facts (if not necessarily his controversial interpretations) are firmly grounded in research, Noble in both books quotes excessively from scholars of fields in which he is not expert. Yet his powerful overarching arguments and his own clear, compelling prose overcome these limitations.

Nevertheless, one wonders about the pervasiveness of the Religion of Technology in the light of the growing scepticism in recent decades about technological progress in general. This scepticism, which reflects inevitable disillusionment when technological utopias do not come about, is partly in reaction to the very technological advances Noble discusses. As Noble recognizes, the technological élites he condemns for their arrogance care little about ordinary people (males and females alike) and would gladly leave them behind on Earth as they pursue glorious space flights and space colonies. They would reproduce only geniuses like themselves through genetic engineering or create computerized virtual minds lasting indefinitely. In fact, Noble connects their indifference to the repeated failure of modern technology to meet basic human needs for all as opposed to fulfilling the selfcentred dreams of a few.

Still, the mundane daily concerns of millions everywhere about technology's profoundly mixed blessings - as detailed in Edward Tenner's Why Things Bite Back: New Technology and the Revenge Effect (Knopf/Fourth Estate, 1996; for a review see Nature 382, 504; 1996) - make the dreams of these engineers and inventors more passéthan avant-garde, more pathetically naive than enviably sophisticated. The transformations those technological élites deem almost inevitable are surely far from certain.

In addition, and partlybecause of the commonplace frustrations and disappointments illuminated by Tenner, there no longer exists in the countries in which these visionaries reside the grass-roots enthusiasm for space programmes, genetic engineering, and other millenarian enterprises that governments and corporations could once take for granted in allocating funds. Paradoxically, then, widespread technological scepticism may offer the world more hope for genuine technological - and social - progress than Noble allows.

Nevertheless, The Religion of Technology is a most significant work that deserves a wide readership. It is a worthy successor to Lewis Mumford's critical histories of technology. $\square$ Howard P. Segal is in the Department of History, University of Maine, 5774 Stevens Hall, Orono, Maine 04469-5774, USA. 